\title{
3,3'-Diindolylmethane inhibits migration and invasion of human cancer cells through combined suppression of ERK and AKT pathways
}

\author{
SHILPI RAJORIA ${ }^{1}$, ROBERT SURIANO ${ }^{1}$, YUSHAN LISA WILSON ${ }^{2}$, STIMSON P. SCHANTZ ${ }^{2}$, \\ AUGUSTINE MOSCATELLO $^{2}$, JAN GELIEBTER ${ }^{1}$ and RAJ K. TIWARI ${ }^{1}$ \\ ${ }^{1}$ Department of Microbiology and Immunology, New York Medical College, Valhalla, New York, NY 10595; \\ ${ }^{2}$ Department of Otolaryngology, New York Eye and Ear Infirmary, New York, NY 10003, USA
}

Received July 22, 2010; Accepted August 31, 2010

DOI: $10.3892 /$ or.2010.1076

\begin{abstract}
Metastasis of cancer is a multifactorial disease and is the main cause of death in patients with malignancy. This disease demands treatments which may target multiple dysregulated cellular pathways in cancer cells. The anti-tumor and anti-metastatic properties of natural products in cancer prevention have been confirmed by several epidemiological studies, with cruciferous vegetables being especially protective against many cancers. In this study, we evaluated the anticarcinogenic effects of 3,3'-diindolylmethane (DIM), which is a bioactive compound present in cruciferous vegetables and a widely used dietary supplement, on events commonly observed during metastasis using in vitro adhesion, migration and invasion assays. Our results indicate that DIM inhibits human cancer cell in vitro proliferation, adhesion, migration and invasion. Western blot analyses show that this inhibition of cell proliferation by DIM is exerted by combined suppression of AKT and ERK pathways. Furthermore, DIM also leads to down-regulation of G1-S cell cycle markers: cyclin D1, cdk6 and cdk4. These findings may lead to development of a novel preventive and/or therapeutic dietary supplement for patients diagnosed with cancer or predisposed to developing certain cancers.
\end{abstract}

\section{Introduction}

Recent dietary and epidemiological studies suggest that a diet rich in fat and meat enhances the risk of developing many types of cancers such as breast, prostate and colorectal while diets rich in fruits and vegetables reduce this predisposition (1-4). These reports suggest that the use of phytochemicals can serve as a promising approach for cancer prevention

Correspondence to: Dr Raj K. Tiwari, Department of Microbiology and Immunology, New York Medical College, Valhalla, NY 10595, USA

E-mail: raj_tiwari@nymc.edu

Key words: 3,3'-diindolylmethane, migration, invasion
(1-4) and has led to intense activity in field of defining dietary chemopreventive agents and molecular targets for cancer chemoprevention. One such potential phytochemical is Indole-3-carbinol (I3C), bioactive compound found in cruciferous vegetables which is responsible for the observed reduced cancer risk in areas with high cruciferous vegetable consumption. We were among the first to recognize $\mathrm{I} 3 \mathrm{C}$ as having anticancer properties (5-7) but the major drawback with clinical use of I3C as an anti-cancer drug is its molecular instability. I3C readily dimerizes into 3,3-diindolylmethane (DIM), which is an acid catalyzed stable compound and does not undergo any further condensation reactions. It is this compound, DIM, which is thought to be the main mediator of the chemopreventive effects of I3C. Most importantly, studies have indicated that long-term consumption of DIM (upto 12 months) does not lead to any toxicity in mice (8), suggesting that DIM can be a promising naturally available bioactive compound which can be used as a potential novel chemopreventive agent.

Although, the complete mechanism responsible for the anticancer properties of DIM is not known, several studies in breast and prostate cancers suggest that DIM inhibits the activity of Akt kinase and prevents nuclear translocation of NF-кB $(9,10)$. Also, it has been reported that DIM exerts its chemopreventive effects in breast cancer by activation of the JNK and p38 pathways (11). Cancer cell invasion and migration has been observed to be targeted by DIM via inhibiting expression of VEGF, MMPs and UPA-uPAR in breast and prostate cancers (12-14). DIM was also observed to inhibit the metastatic propensity of breast and ovarian cancer cells by down-regulating the chemokine receptor CXCR4 and/or its ligand CXCL12 $(15,16)$, both of which are essential for migration of many cancer cell types. Collectively, these studies provide evidence of the anticancer activity of DIM and suggest its utility as a cancer preventive agent.

The objective of the present study was to investigate the chemopreventive properties of DIM in the human cancer cell line HT-29(50-TS). We report for the first time that DIM may have therapeutic ability to act as a chemo-preventive agent against HT-29(50-TS) cancer cells by down-regulating the cell proliferation and metastasis associated events, namely 
migration, adhesion and invasion. We have identified the Akt and ERK pathways as targets of DIM, which are commonly over activated in many types of cancers, potentially leading to the development of a novel preventive and/or therapeutic dietary supplement.

\section{Materials and methods}

Cell culture. KAT50-TS cells were provided by Dr Kenneth B. Ain (VA Medical Center, Lexington, KY). This cell line has been misidentified as of thyroid origin (17) and DNA profiling using the Identifier kit from Applied Biosystems (data not shown) confirmed that KAT50-TS is not of thyroid cancer origin but matches the short tandem repeat (STR) profile of HT-29 colorectal cancer cell line. Thus, by our own convention, we named the cells as HT-29(50-TS). This name identifies the parent cell line, but distinguishes them as unique sub-lines that may have differential responses to similar treatments for HT-29 in another lab. It is cultured in phenol red free RPMI-1640 (Mediatech, Herndon, VA) supplemented with $10 \%$ fetal bovine serum (FBS) (Atlanta Biologicals, Lawrenceville, GA), penicillin 10,000 IU/ml, streptomycin 10,000 $\mu \mathrm{g} / \mathrm{ml}$ (Mediatech), $2 \mathrm{mM}$ L-glutamine (Mediatech), $100 \mathrm{mM}$ MEM sodium pyruvate solution (Mediatech) and $10 \mathrm{mM}$ MEM non-essential amino acids solution (Mediatech).

XTT cell proliferation assay. Two thousand cells in $200 \mu 1$ medium were plated into each well of 96-well plates and incubated overnight to allow cell adherence. The media were removed and 3,3'-diindolylmethane (DIM), kindly provided by Dr Michael Zeligs (BioResponse, Boulder, CO), was added at concentrations of $10,25,50,75,100$ and $500 \mu \mathrm{M}$ in a total volume of $200 \mu \mathrm{l}$ and incubated for 24 and $48 \mathrm{~h}$. The media were discarded and fresh growth media were added without drug followed by $50 \mu 1$ XTT [ $1 \mathrm{mg} / \mathrm{ml}$ in serum-free RPMI + phenazine methosulfate $(25 \mathrm{nM})$ before use]. The plate was read after 4-h incubation in a microplate reader at $450 \mathrm{~nm}$ and reference at $630 \mathrm{~nm}$. The mean OD values were calculated for each dose at the respective time points and the percent survival in the treated cells was calculated by comparing to untreated control and plotted as a function of time and dose.

Clonogenic assay. To determine the effect of DIM on the clonogenicity, HT-29(50-TS) cells were plated in 6-well plates (200 cells per well). The cells were allowed to adhere overnight, after which DIM was added at concentrations of 25 and $50 \mu \mathrm{M}$ or left untreated. After 14 days in culture, the cells were fixed and stained using $0.025 \%$ Coomassie brilliant blue R250 (in 50\% methanol and 10\% acetic acid) to visualize cell colonies. The colonies were counted, and percentage inhibition of clonogenicity and SD were calculated.

Transwell migration assay. Migration assay was performed as described earlier (18). Briefly, BD Biocoat Control Inserts (BD Biosciences, Bedford, MA) with $8-\mu \mathrm{m}$ pore membrane filters were used and $2.5 \times 10^{4}$ cells per well were loaded in insert with or without DIM, and $750 \mu 1$ of growth medium containing 5\% FBS was added in wells. After $18 \mathrm{~h}$ of incubation, cells on the lower surface of the membrane were fixed and stained using $1 \%$ toluidine blue $1 \%$ borax stain. Data are expressed as numbers of counted, migrated cells per X10 field micrograph for each sample well and normalized to those cell counts obtained for the untreated control.

Scratch wound assay. Migratory ability of HT-29(50-TS) cells was also assessed by a scratch wound assay as described earlier (18). Briefly, $5 \times 10^{5}$ cells were plated in a 6-well plate and were allowed to grow to semiconfluent cell monolayers. Subsequently, three vertical wounds were caused per well using a $2.5-\mu 1$ sterile pipette tip. The wounded cell monolayer was then incubated in fresh complete media with or without DIM. The cells were inspected every $3 \mathrm{~h}$ until the scratched cells fully migrated from one end of wound to other and pictures were taken just above and below the horizontal mark using a light microscope at $5 \mathrm{X}$.

Cell adhesion assay. Cells $\left(5 \times 10^{5}\right)$ were plated in 6-well culture dishes with or without DIM and allowed to adhere for $2.5 \mathrm{~h}$. After $2.5 \mathrm{~h}$, medium with non-adhered cells was discarded and wells were gently washed twice with PBS to remove any loosely attached cells. Adhered cells were then counted using $0.4 \%$ trypan blue solution solution (Sigma Chemicals Co). Data expressed as percent decrease in adhered cell count for cells treated with DIM relative to control cells.

Invasion assay. Invasion assay was performed as described earlier (18). Briefly, BD Biocoat growth Factor Reduced Matrigel Invasion chambers (BD Biosciences) with $8-\mu \mathrm{m}$ pore membrane filters coated with matrigel were ussed. Cells $\left(2.5 \times 10^{4}\right)$ resuspended in the RPMI $(500 \mu 1)$ containing $1 \% \mathrm{FBS}$, and/or DIM were added to inserts. Cells were allowed to invade for $18 \mathrm{~h}$ after which cells were stained and counted similarly as for migration assay. Percent invasion was calculated based on the percent of cells invading through the growth Factor Reduced Matrigel Invasion chambers relative to the cells migrating through control membrane. Data are expressed here as invasion index which is the ratio of the percent invasion of the test cell over the percent invasion of a control cell.

Western blot analysis. Whole cell lysate preparation and Western blot analysis were performed as described earlier (18). Briefly, cells were treated with 25 or $50 \mu \mathrm{M}$ DIM for $24 \mathrm{~h}$ followed by lysis. Cell lysates ( $15 \mu \mathrm{g}$ protein) were subjected to SDS-PAGE under reducing conditions as described earlier. The membranes were incubated overnight at $4^{\circ} \mathrm{C}$ with primary antibodies (cyclin D1, CDK4, CDK6, actin and PTEN purchased from Santa Cruz Biotechnology, Santa Cruz, CA and pAKT, AKT, ERK1/2 and pERK1/2 purchased from Cell Signaling Technology) and incubated with the respective horseradish peroxidase (HRP) conjugated secondary antibody, for $2 \mathrm{~h}$ at room temperature. Membranes were developed by ECL substrate (Pierce Rockford, IL) and detected on Denville autoradiography film.

Statistical calculation. Experiments presented here represent three replicates with statistical significance determined using a paired Student's t-test with a probability ( $\mathrm{p}$-value) $\leq 0.05$ used to reject the null hypothesis. 
A

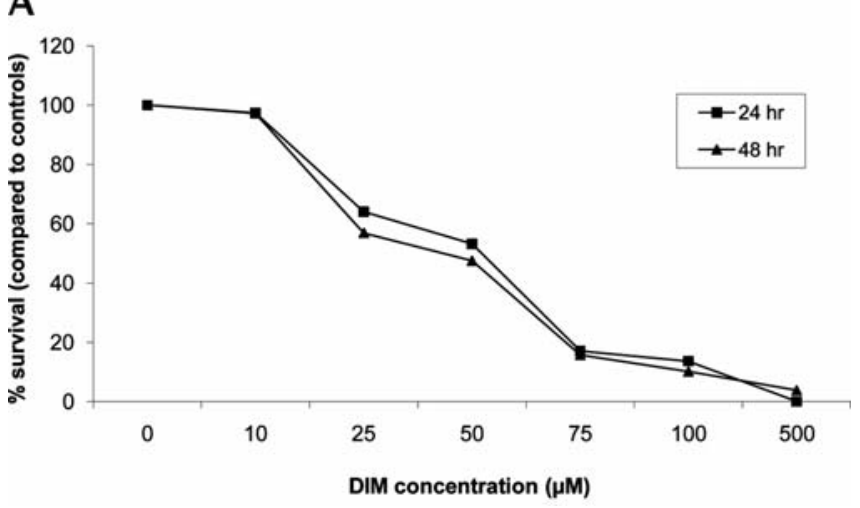

B

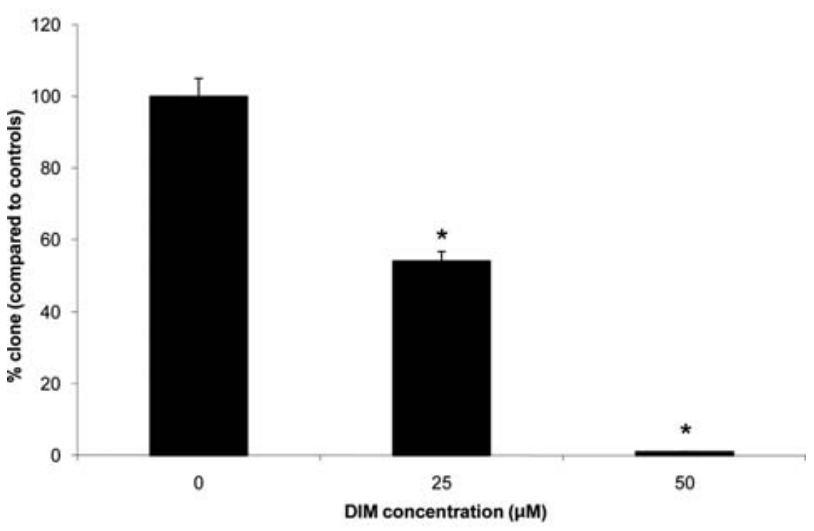

Figure 1. DIM inhibits the growth of human colorectal cancer HT-29(50-TS) cells. (A) Cells were plated at a density of 2000/well in 96-well plates overnight and treated with either DMSO alone or DIM at the concentration of 10-500 $\mu \mathrm{M}$ in DMSO. Percent cell survival was determined by XTT assay after 24 and $48 \mathrm{~h}$ of treatment and plotted as a function of time and dose of DIM. (B) Two hundred cells per well in 6-well plates were allowed to adhere overnight, and 25 or $50 \mu \mathrm{M}$ DIM was added to each well for 14 days. Cell colonies were counted visually and percentage clonogenicity was calculated based on untreated cells which were set as $100 \%$. The asterisk denotes statistically significant differences $(\mathrm{p}<0.05)$ between the indicated samples.

\section{Results}

DIM has antiproliferative effect on HT-29(50-TS). The antiproliferative effects of DIM on HT-29(50-TS) cells were investigated by XTT assay at varying concentrations and time period. Cell survival decreased with increasing doses of DIM and almost total loss of cell viability was observed at $500 \mu \mathrm{M}$ DIM (Fig. 1A). The $\mathrm{IC}_{50}$ was determined to be $50 \mu \mathrm{M}$ DIM and based on IC $_{50}$ value of DIM, 25 and $50 \mu \mathrm{M}$ DIM was used as investigatory concentrations of DIM for all the experiments.

One of the hallmark properties of cancer cells is the ability to divide 'indefinitely' under isolated clonal growth (19). The anticancer effect of DIM on the ability of HT-29 (50-TS) cells to divide indefinitely, thereby on its reproductive ability was evaluated by a clonogenicity cell survival assay. As little as 200 cells per well in 6-well plates were let adhere overnight after which they were treated with 25 or $50 \mu \mathrm{M}$ DIM. The untreated HT-29(50-TS) cells have the ability to form clones, while DIM caused significant, dose dependent inhibition of clonogenicity of these cells (Fig. 1B).
A

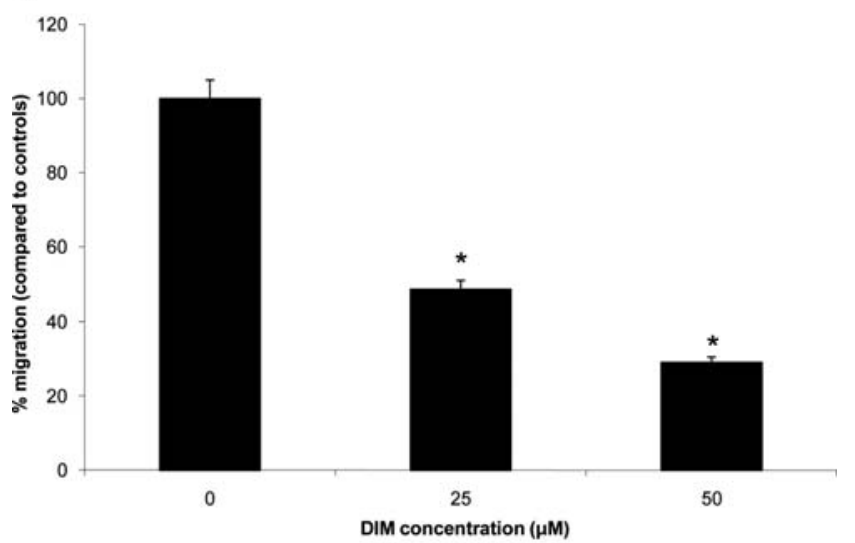

B

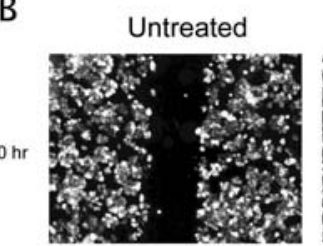

$25 \mu \mathrm{M}$ DIM

$50 \mu \mathrm{M}$ DIM
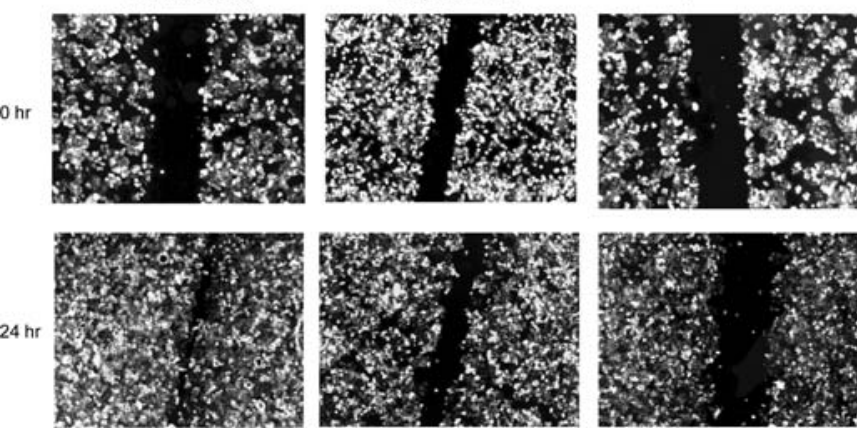

Figure 2. DIM inhibits HT-29(50-TS) cell migration. (A) Migration of HT29(50-TS) cells was analyzed by modified boyden chamber assay using BD Biocoat Control Inserts ( $8-\mu \mathrm{m}$ pore membrane filters). After incubation with DIM for $18 \mathrm{~h}$, cells migrated to the lower surface of the insert were counted microscopically. Data are expressed as numbers of cells counted (migrated cells) per 10X field micrograph for each sample well and normalized to those cell counts obtained for the untreated control. (B) DIM inhibits HT-29(50-TS) cell migration in scratch wound assay. Semiconfluent cells were wounded and recultured in presence of DIM or DMSO alone. The cells were visualized and photographed under $5 \mathrm{X}$ every $3 \mathrm{~h}$ until the cells completely migrated from one end of 'scratch' to other end. The asterisk denotes statistically significant differences $(\mathrm{p}<0.05)$ between the indicated samples.

The treatment with $25 \mu \mathrm{M}$ DIM resulted in $54.2 \%$ clones for HT-29(50-TS) cells with no clones observed with $50 \mu \mathrm{M}$ DIM.

DIM suppresses metastatic phenotype of HT-29(50-TS) tumor cells. Metastasis is a dynamic hallmark of cancer which consists of three essential events; migration of cancer cells from a primary foci to secondary organ, adhesion of cancer cells at this secondary site and invasion of extracellular matrix (ECM) of secondary organ $(19,20)$. Thus, it is conceivable to hypothesize that a drug or compound which can influence the metastatic properties of HT-29(50-TS) cells will be a viable agent for chemoprevention and therapeutics against colorectal cancer. We investigated the effect of DIM on HT-29(50-TS) cell migration by modified boyden chamber and scratch wound assay. The number of HT-29(50-TS) cell migrating through the boyden chamber were significantly decreased by treatment of the cells with DIM in a concentration-dependent manner with only $29 \%$ cells migrating towards chemoattractant when $50 \mu \mathrm{M}$ DIM was present (Fig. 2A). To further evaluate the effect of DIM on the 


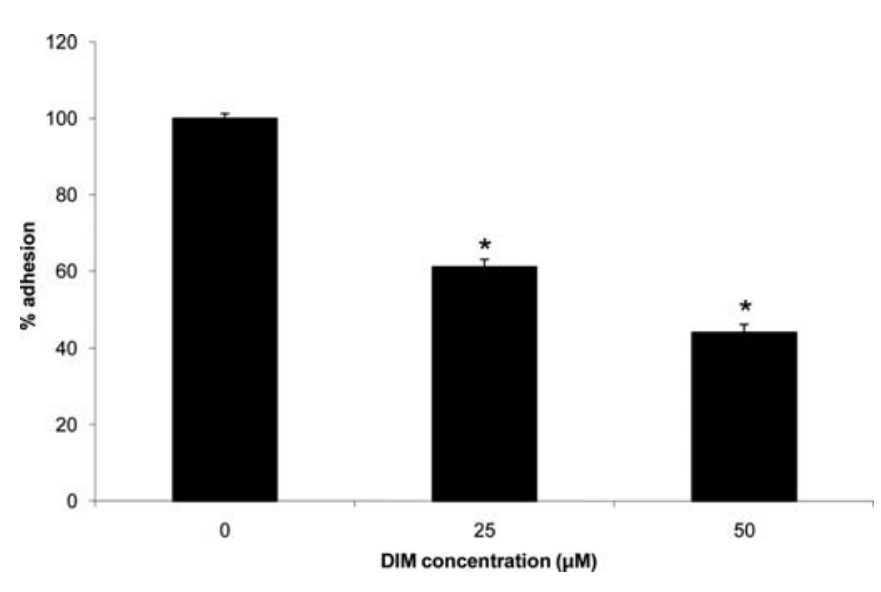

Figure 3. DIM inhibits adhesion of HT-29(50-TS) cells. Cells were suspended in complete medium containing 25 or $50 \mu \mathrm{M}$ DIM and plated for $2.5 \mathrm{~h}$. Viable adhered cells were removed by scraping and counted using trypan blue dye. Data are expressed as \% adhered cells compared to untreated cells which was set to $100 \%$ adhesion. The asterisk denotes statistically significant differences $(\mathrm{p}<0.05)$ between the indicated samples.

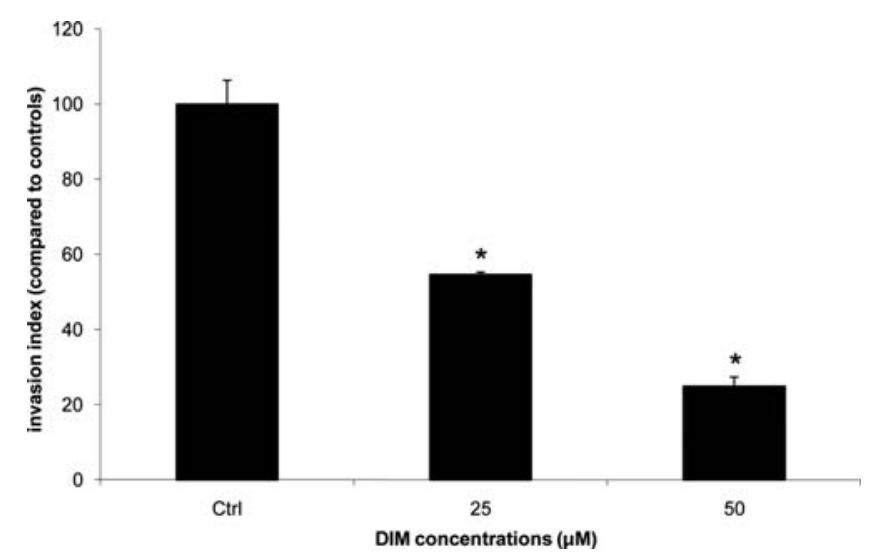

Figure 4. DIM reduces HT-29(50-TS) cell invasion. Invasive properties were analyzed using Matrigel coated Invasion chambers. Cells were resuspended in medium containing 25 or $50 \mu \mathrm{M}$ DIM and allowed to invade for $18 \mathrm{~h}$. Percent invasion was calculated based on the number of cells invading through the growth factor reduced matrigel invasion chambers relative to the cells migrating through control membrane. Cells were counted under a $10 \mathrm{X}$ objective. The asterisk denotes statistically significant differences $(\mathrm{p}<0.05)$ between the indicated samples.

migration of HT-29(50-TS) cells, a scratch wound assay was performed, which is a partial in vivo representation of metastatic phenotype (21). This experiment examined the effect of DIM on migration of these cells based on ability of cells to interact with extracellular matrix in presence of DIM. Cells were grown in monolayers in 6-well plates followed by formation of three vertical scratches per well and incubation with 25 or $50 \mu \mathrm{M}$ DIM or left untreated. We discovered that in presence of DIM the ability of these cells to migrate from one end of 'wound' to the other was significantly reduced (Fig. 2B) with $<20 \%$ cells migrating (as observed visually) in presence of $50 \mu \mathrm{M}$ DIM, suggestive of anti-migratory potential of DIM on colorectal cancer cells.
As mentioned earlier, in order to metastasize, tumor cells have to adhere to the ECM of secondary organ. We evaluated the effect of DIM on adhesion of HT-29(50-TS) cells by performing an adhesion assay. Cells $\left(5 \times 10^{5}\right)$ were resuspended in medium containing 25 or $50 \mu \mathrm{M}$ DIM or left untreated and plated onto 6-well culture dishes. After $2.5 \mathrm{~h}$ adhered cells were counted and \% adhesion was calculated (Fig. 3). A significant decrease in adhesion was observed when cells were treated with DIM in a dose-dependent manner with over 55\% decrease on adhesion of HT-29(50-TS) cells with $50 \mu \mathrm{M}$ DIM.

Formation of secondary metastatic foci requires invasion of the ECM of secondary organs by cancer cells and the inhibition of this invasion potential of cancer cells as a strategy of cancer therapy has been widely investigated. The effect of DIM on the invasive potential of HT-29(50-TS) cells was assayed through the use of a transwell invasion chamber coated with biological matrix in vitro (matrigel). We discovered that DIM causes $>45 \%$ inhibition in the invasion potential of HT-29(50-TS) cells by concentration as low as $25 \mu \mathrm{M}$ (Fig. 4), suggesting that DIM may potentially act as an effective anti-metastatic agent.

DIM treatment suppresses Akt and ERK1/2 activation. $\mathrm{PI} 3 \mathrm{~K} / \mathrm{Akt}$ and MAPK pathways are key survival pathways which operate in cells in response to growth factor stimuli leading to cell growth, development, survival and apoptosis, and when altered they can be a predominant cause of metastasis and tumorigenesis (22-24). They are generally overexpressed in colorectal cancer patients, suggesting that DIM mediated inhibition of PI3K/Akt and MAPK signaling pathways in HT-29(50-TS) cells would have clinical utility. Cells were treated with 25 or $50 \mu \mathrm{M}$ DIM for $24 \mathrm{~h}$ followed by whole cell lysate preparation and Western blot analysis. We discovered that treatment of HT-29(50-TS) cells with DIM resulted in a dose-dependent up-regulation of PTEN, a suppressor of Akt, and down-regulation of the active pAKT $\left(\mathrm{Ser}^{473}\right)$. The levels of total Akt were comparable with no significant changes in PI3K levels (data not shown). We also discovered that DIM treatment causes a significant downregulation in levels of pERK1/2 at $24 \mathrm{~h}$ (Fig. 5). Our results show that DIM inhibits Akt and ERK pathways by virtue of down-regulation of phosphorylation of their key molecules, indicating the Akt and ERK1/2 as possible targets of DIM.

Effect of DIM treatment on cyclin D1, cdk4 and cdk6 cell cycle markers. Progression through cell cycle and enhanced metastasis involves activation of cyclin dependent kinases (CDKs) and their positive regulators cyclins. Increased expression of cyclin D1 and CDKs in colorectal cancer cell lines and human colorectal cancer has been correlated with increased tumorigenicity $(25,26)$. We investigated whether DIM affects these critical proteins involved in the G1-S transition of cell cycle. HT-29(50-TS) cells were treated with 25 or $50 \mu \mathrm{M}$ DIM for $24 \mathrm{~h}$ and whole cell lysates were used to detect the steady-state levels of cyclin D1, CDK4 and CDK6. A down-regulation in the expression of cyclin D1, CDK4 and CDK6 was observed with increasing concentration of DIM (Fig. 6), suggestive of its potential to alter the ability of cancer cells to metastasize. 

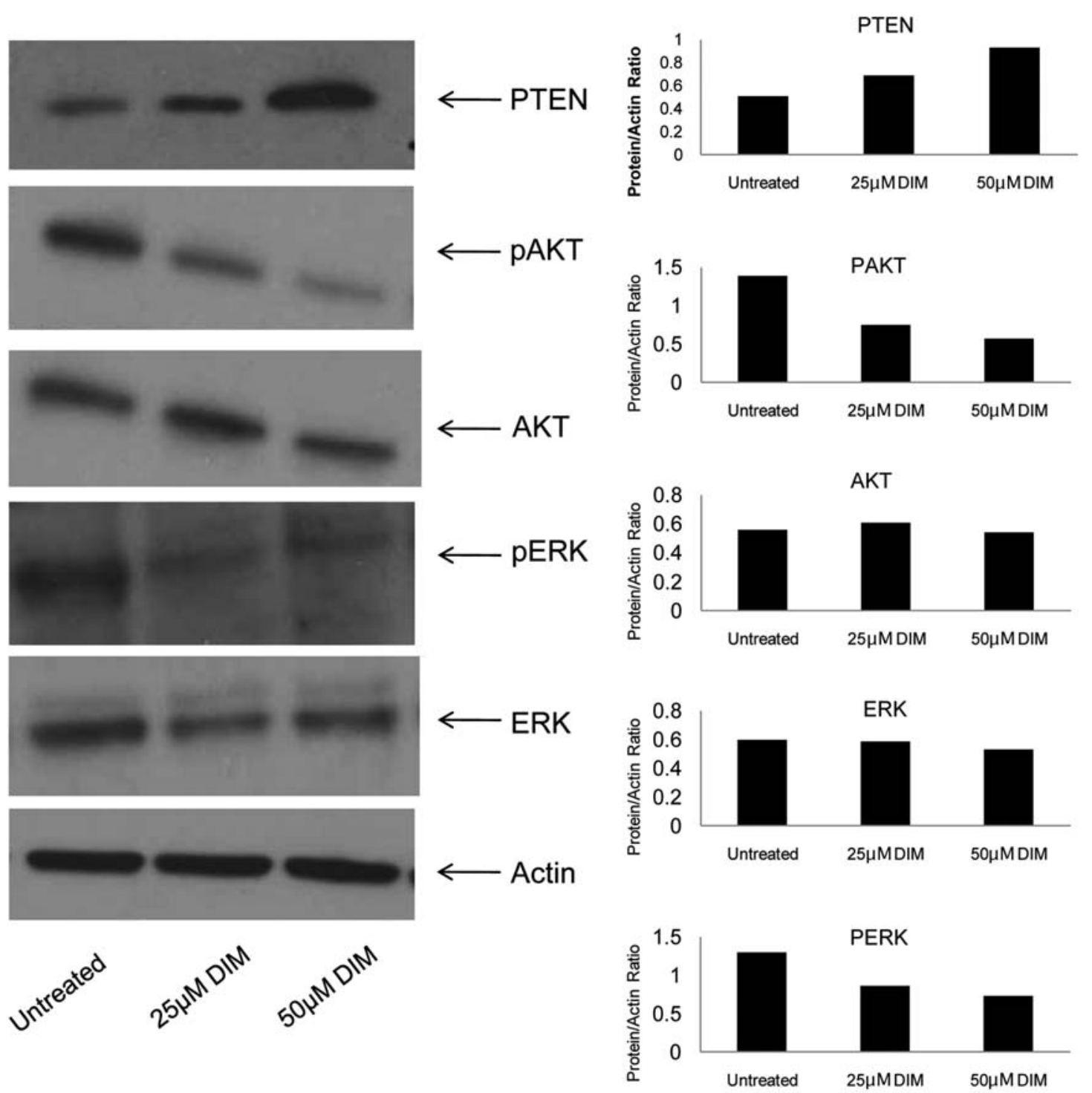

Figure 5. DIM down-regulates the expression of phosphorylated Akt and ERK. HT-29(50-TS) cells were treated with 25 or $50 \mu \mathrm{M}$ DIM for $24 \mathrm{~h}$ and protein levels of Akt, pAkt, PTEN, ERK and pERK were determined in whole cell lysates by Western blot analysis. B-actin was used as loading control.

\section{Discussion}

Epidemiological studies suggest that consumption of a diet rich in fruits and vegetables reduces the risk of cancer, especially digestive system related cancers, such as colorectal cancer (27). These observations have led to the latest global strategy for cancer prevention, which recommends 'five-a-day' consumption of a variety of fruits and vegetables (28). Consequently, these observations have also shifted focus of cancer research in recent years to identification and characterization of naturally occuring chemopreventive agents isolated from plants (29). In this regard, many diverse phytonutrients such as retinoic acid, sulforaphane, I3C and most importantly DIM (30) have been identified as having promising chemopreventive and/or anticancer properties against various cancer types.

In the present study, DIM was analyzed for its anticancer, anti-invasion and anti-migration potential against colorectal cancer. DIM has been reported to exert its anticancer effects against several cancers such as breast, prostate and ovarian cancers. In addition, previous studies have shown that regulation of cell growth and metastasis in normal cells is a complex process that involves multiple cell signaling networks such as MAPK and Akt pathways (22-24). For normal cell growth and proliferation, Ras/Raf activates MAPK ERK1 and ERK2 and PI3K phosphorylates Akt, resulting in activation of several downstream targets resulting in cell growth and proliferation and anti-apoptotic signals. As a result of genetic instability, PI3K/Akt and MAPK pathways become over active, which is a common cause of several cancers in humans, including colorectal cancer. In particular, overexpression of the members of Akt and Erk pathways are frequently associated with poor prognosis and more metastatic aggressive phenotype of colorectal cancer (31). This makes these signaling pathways specific targets to form basis for the development of novel therapeutic agents for this cancer.

An important finding in this present study is a concurrent down-regulated expression of phosphorylated forms of Akt and ERK. Our results clearly demonstrated that DIM acts as an anti-cancer compound against colorectal cancer by down- 

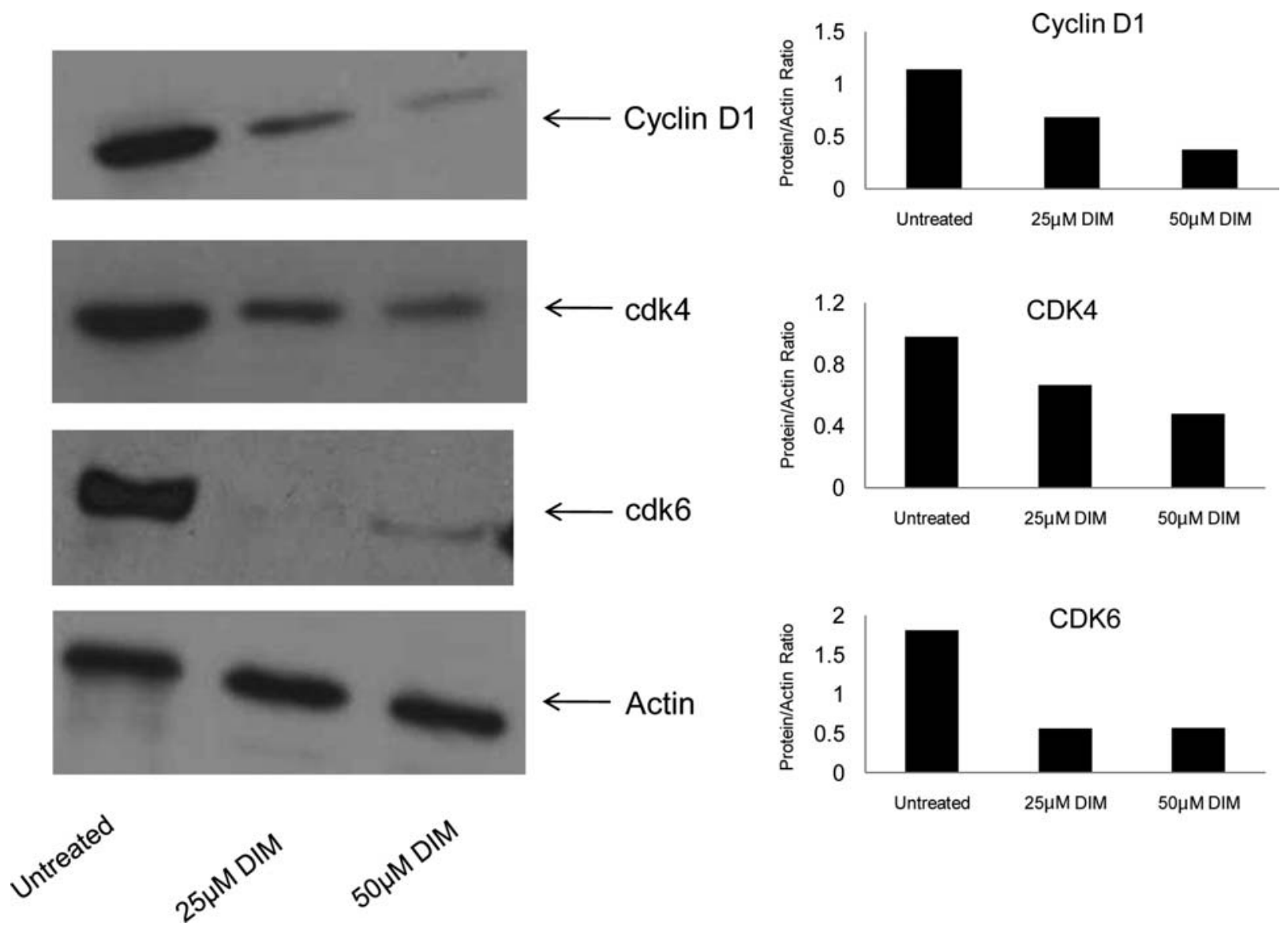

Figure 6. DIM down-regulates the expression of cyclin D1, cdk4 and cdk6 in HT-29(50-TS) cells. HT-29(50-TS) cells were either untreated or treated with 25 or $50 \mu \mathrm{M}$ DIM for $24 \mathrm{~h}$ and whole cell lysates were used for Western blot analysis of G1-S cell cycle transition markers, cyclin D1, cdk4, and cdk6. B-actin was used as loading control.

regulating proliferation and clonogenicity of HT-29(50-TS) cells. DIM also targets the in vitro metastasis of HT-29(50TS) cells as evidenced by decreased migration, adhesion and invasion of these cells in a cell culture based model. We discovered that this down-regulation in the metastatic phenotype of HT-29(50-TS) cells by treatment with DIM is probably through suppression of ERK1/2 and Akt pathway. Specifically, DIM targets and inhibits the phosphorylation of key molecules ERK1/2 and Akt with a concomitant increase in levels of PTEN. Mutations in the tumor suppressor gene PTEN, a negative regulator of Akt, have been observed in several cancer types, including colorectal cancer. Expression of PTEN in colorectal cancer cells suppresses tumor cell growth and its down-regulation in colorectal cancer cells leads to tumorigenicity (32), indicating a strong role of PTEN in colorectal cancer etiology, and making Akt and ERK pathways an ideal target of DIM.

In addition, our study also shows that DIM down-regulates the expression of important cell cycle markers required for G1-S transition. The involvement of AKT and ERK signaling pathways in regulating cell cycle progression is well understood. Phosphorylated AKT leads to activation of Raf-1, p21 and IKK which trigger the expression of antiapoptotic proteins. Furthermore, phosphorylated ERK leads to positive regulation of cell cycle progression by increase in cyclin-CDK complexes and up-regulation of E2F family transcription factors. In the present study, DIM decreased protein levels of cyclin D1, CDK4 and CDK6 in human colorectal cancer cells. Therefore, alteration of these mechanisms by DIM appears to significantly contribute to the anti-metastatic and anti-proliferative activities of this compound.

In conclusion, this report suggests that DIM inhibits cell migration, invasion and adhesion in human colorectal cancer cells through suppression of ERK and AKT pathways. In agreement with the reports of potential for antiproliferative activites of DIM in colorectal cancer cells, we found antimigration and anti-invasion potential of DIM in human colorectal cancer cells. This extends the effects of DIM beyond those traditionally implicated in chemoprevention, such as inhibition of cell cycle progression and anti-proliferation; and suggests that DIM may also act by blocking additional stages of colorectal cancer progression such as those stages resulting in invasion and migration and thus highly dreadful metastatic colorectal cancer.

\section{Acknowledgements}

The study was supported by grants from National Cancer Institute 1R01CA131946 and clinical funding from New York Eye and Ear Infirmary, New York, NY. We also thank Dr Michael Zeligs (Bioresponse, Boulder, CO) for providing DIM for all the experiments. 


\section{References}

1. American Cancer Society. Colorectal Cancer Facts \& Figures 2008-2010. American Cancer Society, Atlanta, 2008.

2. Johnson IT: New approaches to role of diet in prevention of cancers of the alimentary tract. Mutat Res 551: 9-28, 2004.

3. Sarkar FH and $\mathrm{Li} \mathrm{Y}$ : Harnessing the fruits of nature for the development of multi-targeted cancer therapeutics. Cancer Treat Rev 35: 597-607, 2009.

4. Bode AM and Dong Z: Cancer prevention research - then and now. Nat Rev Cancer 9: 508-516, 2009.

5. Ashok BT, Chen YG, Liu X, Garikapaty VP, Seplowitz R, Tschorn J, Roy K, Mittelman A and Tiwari RK: Multiple molecular targets of indole-3-carbinol, a chemopreventive anti-estrogen in breast cancer. Eur J Cancer Prev 2: S86-S93, 2002.

6. Garikapaty VP, Ashok BT, Chen YG, Mittelman A, Iatropoulos M and Tiwari RK: Anti-carcinogenic and anti-metastatic properties of indole-3-carbinol in prostate cancer. Oncol Rep 13: 89-93, 2005.

7. Tiwari RK, Guo L, Bradlow HL, Telang NT and Osborne MP: Selective responsiveness of human breast cancer cells to Indole3-carbinol, a chemopreventive agent. J Natl Cancer Inst 86: 126-131, 1994

8. Leibelt DA, Hedstrom OR, Fischer KA, Pereira CB and Williams DE: Evaluation of chronic dietary exposure to indole3-carbinol and absorption-enhanced 3,3'-diindolylmethane in sprague-dawley rats. Toxicol Sci 74: 10-21, 2003.

9. Li Y, Wang Z, Kong D, Murthy S, Dou QP, Sheng S, Reddy GP and Sarkar FH: Regulation of FOXO3a/B-catenin/GSK-3ß signaling by 3,3'-diindolylmethane contributes to inhibition of cell proliferation and induction of apoptosis in prostate cancer cells. J Biol Chem 282: 21542-21550, 2007.

10. Rahman KM, Ali S, Aboukameel A, Sarkar SH, Wang Z, Philip PA, Sakr WA and Raz A: Inactivation of NF-кB by 3,3'diindolylmethane contributes to increased apoptosis induced by chemotherapeutic agent in breast cancer cells. Mol Cancer Ther 6: 2757-2765, 2007.

11. Xue L, Firestone GL and Bjeldanes LF: DIM stimulates IFNgamma gene expression in human breast cancer cells via the specific activation of JNK and p38 pathways. Oncogene 24: 2343-2353, 2005

12. Kong D, Li Y, Wang Z, Banerjee S and Sarkar FH: Inhibition of angiogenesis and invasion by 3,3'-diindolylmethane is mediated by the nuclear factor- $\kappa \mathrm{B}$ downstream target genes MMP-9 and uPA that regulated bioavailability of vascular endothelial growth factor in prostate cancer. Cancer Res 67: 3310-3319, 2007.

13. Ahmad A, Kong D, Sarkar SH, Wang Z, Banerjee S and Sarkar FH: Inactivation of uPA and its receptor uPAR by 3,3'-diindolylmethane (DIM) leads to the inhibition of prostate cancer cell growth and migration. J Cell Biochem 107: 516-527, 2009.

14. Ahmad A, Kong D, Wang Z, Sarkar SH, Banerjee S and Sarkar FH: Down-regulation of uPA and uPAR by 3,3'diindolylmethane contributes to the inhibition of cell growth and migration of breast cancer cells. J Cell Biochem 108: 916-925, 2009.
15. Hsu EL, Chen N, Westbrook A, Wang F, Zhang R, Taylor RT and Hankinson O: CXCR4 and CXCL12 down-regulation: a novel mechanism for the chemoprotection of 3,3'-diindolylmethane for breast and ovarian cancers. Cancer Lett 265: 113-123, 2008.

16. Hsu EL, Chen N, Westbrook A, Wang F, Zhang R, Taylor RT and Hankinson O: Modulation of CXCR4, CXCL12, and tumor cell invasion potential in vitro by phytochemicals. J Oncol 2009: 491985, 2009

17. Schweppe RE, Klopper JP, Korch C, Pugazhenthi U, Benezra M, Knauf JA, Fagin JA, Marlow L, Copland JA, Smallridge RC and Haugen BR: Deoxyribonucleic acid profiling analysis of 40 human thyroid cancer cell lines reveals cross-contamination resulting in cell line redundancy and misidentification. J Clin Endocrinol Metab 93: 4331-4341, 2008.

18. Rajoria S, Suriano R, Shanmugam A, Wilson YL, Schantz SP, Geliebter J and Tiwari RK: Metastatic phenotype is regulated by estrogen in thyroid cells. Thyroid 20: 33-41, 2010.

19. Hanahan D and Weinberg RA: The hallmarks of cancer. Cell 100: 57-70, 2000.

20. Gupta GP and Massagué J: Cancer metastasis: building a framework. Cell 127: 679-695, 2006.

21. Liang CC, Park AY and Guan JL: In vitro scratch assay: a convenient and inexpensive method for analysis of cell migration in vitro. Nat Protoc 2: 329-333, 2007.

22. Cheng GZ, Zhang W and Wang LH: Regulation of cancer cell survival, migration, and invasion by Twist: AKT 2 comes to interplay. Cancer Res 68: 957-960, 2008.

23. Hennessy BT, Smith DL, Ram PT, Lu Y and Mills GB: Exploiting the PI3K/AKT pathway for cancer drug discovery. Nat Rev Drug Discov 4: 988-100, 2005.

24. Yuan TL and Cantley LC: PI3K pathway alterations in cancer: variations on a theme. Oncogene 27: 5497-5510, 2008.

25. Palmqvist R, Stenling R, Oberg A and Landberg G: Expression of cyclin D1 and retinoblastoma protein in colorectal cancer. Eur J Cancer 34: 1575-1581, 1998.

26. Arber N, Hibshoosh H, Moss SF, Sutter T, Zhang Y, Begg M, Wang S, Weinstein IB and Holt PR: Increased expression of cyclin D1 is an early event in multistage colorectal carcinogenesis. Gastroenterology 110: 669-674, 1996.

27. La Vecchia C: Mediterranean diet and cancer. Public Health Nutr 7: 965-968, 2004

28. Heber D: Vegetables, fruits and phytoestrogens in the prevention of diseases. J Postgrad Med 50: 145-149, 2004.

29. Cooke D, Steward WP, Gescher AJ and Marczylo T: Anthocyans from fruits and vegetables: does bright colour signal cancer chemopreventive activity? Eur J Cancer 41: 1931-1940, 2005.

30. Surh YJ: Cancer chemoprevention with dietary phytochemicals. Nat Rev Cancer 3: 768-780, 2003.

31. Dihlmann S, Kloor M, Fallsehr C and von Knebel Doeberitz M: Regulation of AKT1 expression by beta-catenin/Tcf/Lef signaling in colorectal cancer cells. Carcinogenesis 26: 1503-1512, 2005.

32. Sawai H, Yasuda A, Ochi N, Ma J, Matsuo Y, Wakasugi T, Takahashi H, Funahashi H, Sato M and Takeyama H: Loss of PTEN expression is associated with colorectal cancer liver metastasis and poor patient survival. BMC Gastroenterol 8: 56, 2008. 